\title{
Characterization of physical and chemical properties of biodiesel produced from Jatropha curcas seeds oil cultivated in Rwanda
}

\author{
Jean Ntaganda ${ }^{1}$, Andre Ndagijimana ${ }^{2,}$, , Oscar Benimana ${ }^{1}$ \\ ${ }^{1}$ Department of Chemistry, College of Science and Technology, University of Rwanda, Butare, Rwanda \\ ${ }^{2}$ Institute of Scientific and Technological Research (IRST), Butare, Rwanda
}

\section{Email address:}

ndereyafr@yahoo.fr (N. Andre)

\section{To cite this article:}

Jean Ntaganda, Andre Ndagijimana, Oscar Benimana. Characterization of Physical and Chemical Properties of Biodiesel Produced from Jatropha Curcas Seeds Oil Cultivated in Rwanda. Science Journal of Energy Engineering. Vol. 2, No. 2, 2014, pp. 8-12.

doi: $10.11648 /$ j.sjee.20140202.11

\begin{abstract}
A yield of $26.88 \%$ of seed oil was obtained from Jatrophacurcas cultivated in Rwanda. Within 2 hours of reaction, the methyl ester (Biodiesel) was produced at a yield of $85.3 \%$ from obtained oil through direct base-catalysed trans-esterification process using methanol and sodium hydroxide as alcohol and catalyst. The proportion of $0.6 \mathrm{~g}$ of $\mathrm{NaOH}$ in $20 \mathrm{~mL}$ of methanol with $100 \mathrm{~mL}$ of Jatropha oil was the best ratio for making the biodiesel. The biodiesel obtained had $85.03 \%$ of ester content, 0.878 and 7.891 Centistokes (at $20^{\circ} \mathrm{C}$ ) of specific gravity and viscosity respectively. The other physico-chemical properties were also characterized.
\end{abstract}

Keywords: Jatropha Curcas, Seed Oil, Biodiesel, Physico-Chemical Analysis

\section{Introduction}

In today's societies there are diminishing petroleum reserves and increasing environmental consequences of exhaust gases from petroleum-fuelled engines [1-3]. Thus, fossil fuel is a problem both in developed and developing countries $[4,5]$. As a remedy, biodiesel as an alternative fuel for diesel engines is becoming increasingly important. Biofuels produced from plants and agricultural wastes may have the potential to cut global warming pollution, enhance our energy security, and strengthen local economies.

The one way of reducing the biodiesel production costs and avoids consequences of environment pollution and famine is to use the less expensive feedstock containing fatty acids such as inedible oils, animal fats, and waste food oil and by- products of the refining vegetables oils [6].

Jatrophacurcas L., atropical plant belonging to the family of Euphorbiaceae, is cultivated mainly as a hedge in many Latin American, Asian and African countries. $J$. curcas is famous for being a potential source of raw material for biodiesel. Its popularity stems from the widespread general knowledge that it is a non-edible, oilyielding tree, well adapted to marginal areas with poor soil and low rainfall, where it grows without competing with annual food crops.

Trypsin inhibitors, lactins, saponins, curcin and toxalbumins, derivatives of 12-deoxy-16-hydroxy phorbolisolated from Jatropha curcas might cause side effects [7]. Those compounds are mainly present in the seed and the latex and could lose their toxicity when the seeds are roasted [8-10]. The seeds from J.curcas have been reported to be orally toxic to humans, rodents and ruminants and phorbol esters have been identified as the main toxic agent. Pure phorbol esters can kill when administered in quantities of micrograms. However, the phorbol esters consist also a family of compounds known to cause a large number of biological effects such as tumor promotion and inflammation [10].

The fact that Jatropha curcas seed oil cannot be used for nutritional purposes without detoxification makes its use as biofuel source very attractive $[8,11,12]$. Biodiesel could be used to help alleviate the energy crisis and generate income in rural areas of developing countries $[1,13]$. There are many other uses of $J$. curcas. Traditionally, the plant has 
been used as a hedge and living fence, not edible by livestock. Growing Jatropha reclaims eroded and waste land. The seed oil can be used as a fuel for lighting and is a raw material for making high quality soap saponification [14]. Residue from seed pressing, relatively rich in nitrogen could be used either by a power station operating by biomass or as a good organic fertilizer [2].The toxalbumine obtained in this plant could also be used in the manufacture of pesticides and insecticides or for medicinal purposes $[2,4]$.

The biodiesel refers to lower alkyl esters of long-chain fatty acids that are synthesized by transesterification with lower carbon chain alcohols. Transesterification consist of the displacement of alcohol from an ester by another alcohol in a process similar to hydrolysis. This process has been widely used to reduce the viscosity of tri-acylglycerids $[5,15]$. The above stepwise reaction occurs through the successive formation of di-and mono-glycerids as intermediate products. After the reaction period, the glycerol rich phase is separated from the ester layer either by decantation or centrifugation. It has been reported that the oil feedstock for alkaline transesterification should not contain more than 1\% Free Fatty Acids (FFA) and 0.05\% water. If the FFA level exceeds this threshold, saponification hinders the separation of alkyl esters from glycerin and reduces the alkyl ester yield [2]. The removal of fats and oils from their natural sources is the first step in the overall process. Each type of oil source requires special techniques which are usually not applicable to other sources [16]. Rendering, pressing and solvent extraction are the most common methods for the recovery of fats and oils $[17,18]$.

\section{Material and Methods}

\subsection{Materials}

The seeds of Jatropha curcas were harvested from farmer's fields at Bugarama Sector, Rusizi District, Western Province of Rwanda. The seeds were selected according to their condition; damaged seeds were discarded while seeds in good condition were cleaned, de-shelled and dried. Seeds were grounded using grinder prior to extraction. Soxhlet assemblage, rotary evaporator, pyknometer, viscosimeter of Ostwald, refractometer, atomic absorption spectrophotometer (AAS 240 Varian) and spectrophotometer UV were used. The n-hexane, dichloromethane, methanol, acetic acid, deionized water, phenolphtalein, ethanol, sodium thiosulphate $\left(\mathrm{Na}_{2} \mathrm{SO}_{3}\right)$, chloroform, diethylic ether, caustic soda $(\mathrm{NaOH})$, potassic soda $(\mathrm{KOH})$, potassium iodide $(\mathrm{KI})$, hydrochloric acid $(\mathrm{HCl})$ were analytical reagent grade.

\subsection{Extraction of J. Curcas Seed Oil}

$500 \mathrm{~g}$ of crushed Jatropha curcas seeds were defatted in a soxhlet extractor apparatus by heating for 6 hours on a heating mantle using $800 \mathrm{~mL}$ of $\mathrm{n}$-hexane. The extracted lipid was obtained by evaporating the solvent using rotary evaporator. Extracted seed oil remained in flask was removed and stored in cool place for biodiesel making and subsequent physico-chemical analysis.

\subsection{Transesterification Reaction}

The transesterification was carried out in a lab scale biodiesel reactor and followed a general reaction for making biodiesel $[13,19]$ :

$$
\begin{gathered}
\text { Organic oil (Jatropha oil) }+ \text { Alcohol }+ \text { Catalyst } \rightarrow \\
\text { Methyl esters (Biodiesel) }+ \text { Glycerol }
\end{gathered}
$$

Different solutions of $10 \mathrm{~mL}$ of $\mathrm{MeOH}$ in which $0.1,0.2$, $0.3,0.4,0.5,0.6,0.7 \mathrm{~g}$ of $\mathrm{NaOH}$ were added separately, and then $2 \mathrm{~mL}$ of each solution was separately mixed with $10 \mathrm{~mL}$ of $J$. curcas seed oil for 2 hours. Each sample of the mixture was poured in a test tube and then rested for 30 minutes. Two layers have been formed in the resting mixture; the upper layer is biodiesel whereas the bottom layer is glycerol. We used the best proportion found in these tests to make a bigger amount of biodiesel.

Specified amount of $\mathrm{NaOCH}_{3}(0.6 \mathrm{~g}$ of $\mathrm{NaOH}$ dissolved in $20 \mathrm{~mL}$ of $\mathrm{MeOH}$ ) and $100 \mathrm{~mL}$ of $J$. curcas oil, were placed in a $250 \mathrm{~mL}$ round bottom flask. Mixture was stirred $(600 \mathrm{rpm})$ at a temperature of $65^{\circ} \mathrm{C}$ for 2 hours in order to complete the transesterification reaction. Then, the reaction mixture was transferred to a separating funnel for separation of two phases at which the sedimentation time has been increased to 1 hour. Of the two separated phases, the upper phase consisted of methyl esters with small amounts of impurities such as residual alcohol, glycerol and partial glycerides, while the lower was the glycerol. The upper methyl ester layer collected was further purified by distilling residual methanol at $80^{\circ} \mathrm{C}$. Some other traces of impurities such as remaining catalyst, residual methanol and glycerol were removed by successive rinses with distilled water. Residual water was then removed by drying esters with $\mathrm{Na}_{2} \mathrm{SO}_{4}$, followed by filtration using Whatman filter paper N.42.The yield of methyl esters was calculated using the following formula:

$$
\text { Yield of methyl esters }(\%)=\frac{\text { Grams of methyl esters produced }}{\text { Grams of seed oil used in reaction }} 100
$$

\subsection{Physico-chemical Properties Analysis}

Chemical and physical properties of $J$. curcas biodiesel have been tested including specific gravity, density, viscosity, refractive index, saponification value, acid value, free fatty acid (FFA), ester value, methanol solubility test, iodine value, peroxide value, and the unsaponifiable matters. The general methods used have been previously reported by different authors[1,2]. 


\section{Results and Discussions}

\subsection{Seed Oil Extraction}

After shelling and crushing the seeds, a yield of $56 \%$ (weight percentage) of whole seeds was obtained. In the process of extraction; different yields for many steps of the experiment have been obtained. The oil extraction with n$\mathrm{C}_{6} \mathrm{H}_{14}: \mathrm{CH}_{2} \mathrm{Cl}_{2}(9: 1)$ and a duration of three hours showed a better yield $(48.8 \%)$ than others (Table 1$)$.

Table 1. Yields of extraction of J.curcas seed oil

\begin{tabular}{|c|c|c|c|c|}
\hline & $1^{\text {st }}$ extraction & $2^{\text {nd }}$ extraction & $3^{\text {rd }}$ extraction & $4^{\text {th }}$ extraction \\
\hline Solvent(s) used (mL) & $\mathrm{n}-\mathrm{C}_{6} \mathrm{H}_{14}$ & $\mathrm{n}-\mathrm{C}_{6} \mathrm{H}_{14}-\mathrm{CH}_{2} \mathrm{Cl}_{2}(9: 1)$ & $\mathrm{n}-\mathrm{C}_{6} \mathrm{H}_{14}-\mathrm{CH}_{2} \mathrm{Cl}_{2}(9: 1)$ & $\mathrm{n}-\mathrm{C}_{6} \mathrm{H}_{14}-\mathrm{CH}_{2} \mathrm{Cl}_{2}(9: 1)$ \\
\hline Yields in weight $\%$ & 41.8 & 40.9 & 44.8 & 48.8 \\
\hline Yields from whole seeds in weight $\%$ & 23.4 & 22.9 & 25.1 & 16.9 \\
\hline Duration of extraction & 3 hours & 3 hours & 24 hours & 3 hours \\
\hline
\end{tabular}

\subsection{Transesterification Reaction}

The extensive preliminary experimentations indicated that it is more efficient to fix reaction temperature at $65^{\circ} \mathrm{C}$, agitation rate at $400 \mathrm{rpm}$, and reaction time at 2 hours. As results, biodiesel was produced at $85.3 \%$ (yield in weight percentage) which had clear yellow color and had $95.03 \%$ of Fatty Acid Methyl Esters (FAME).This means that in $100 \mathrm{~g}$ of biodiesel we had $95.03 \mathrm{~g}$ of FAME biofuel, and Ashok biodiesel had $99.6 \%$ of ester content in $\mathrm{w} \%$. Comparative results have been obtained with Palm kernel oil transesterification $(87.4 \%)$ and J.curcas oil transesterification $(88.2 \%)$ within 30 minutes of experiment [20,21]. A mixture of glycerin and soaps obtained in the place of pure glycerin, could be due to the high content of FFA and water in produced J. curcas oil.

\subsection{Physico-Chemical Properties}

The physico-chemical properties results obtained are presented in Table 2 and these results were compared with the Jatropha oil by Akintayo[22] and the biodiesel from Jatropha oil by Ashok[23]. In fact, there are some results such as specific gravity and refractive index which are close to those obtained by Akintayo and Ashok. Besides, the specific gravity obtained in this study falls within the limit specified for biodiesel fuel in Europe (EN14214:0.86-0.90), Australia (ONC1191: 0.85-0.89), Czech Republic (CSN656507: 0.87-0.89), Germany (DINV51606:0.8750.90), Sweden (SS155436:0.87-0.90) and Italy
(UNI10635:0.86-0.90) [15,21].

For chemical properties analyses, saponification value, iodine value and unsaponifiable matters obtained were higher than those observed by[22]. The acid value was lower than that of Akintayo Jatropha oil value but the obtained biodiesel showed higher acid value $(\mathrm{pH} 5)$ than that of Ashok Jatropha biodiesel. These may be justified by the soil on which Jatropha trees are cultivated on. If it is basic soil it would have many Linolenic fatty acids which increase its iodine value. And this is justified by the iodine value obtained which is in the range of siccative oil i.e. between $131-237 \mathrm{~g}$ of $\mathrm{I}_{2} / 100 \mathrm{~g}$ of oil. The peroxide value $(4.4 \mathrm{mg} / \mathrm{Kg})$ of obtained biodiesel was very high as before the transesterification reaction the produced $J$. curcus seeds oil has been preheated at $100^{\circ} \mathrm{C}$ in order to eliminate the water content.

Regarding minerals content, calcium (302.5ppm) was higher than magnesium (85ppm) and phosphorus (79.9ppm). Also, J. curcas oil obtained had $71.25 \mathrm{ppm}$ of lead $(\mathrm{Pb})$, dangerous for biofuel because of its toxicity. However, its quantity is lower than the limit of $0.15 \mathrm{~g} / \mathrm{L}(150 \mathrm{ppm})$ in Europe but higher than the limit of $0.0267 \mathrm{~g} / \mathrm{L}(26.7 \mathrm{ppm})$ in United States for fossil fuel [24]. This fact could be justified by the considerations that the J.curcas plants analyzed are cultivated on volcanic soil and they are heavy metals bioaccumulative plants. Additionally they are also cultivated near a main road and the vehicles which use fossil fuels had contaminated them by their exhaust gases.

Table 2. Physico-chemical properties results of J.curcas oil and biodiesel.

\begin{tabular}{|c|c|c|c|c|}
\hline \multirow[t]{2}{*}{ Properties } & \multicolumn{2}{|l|}{ J.curcas oil } & \multicolumn{2}{|l|}{ Biodiesel } \\
\hline & Our results & Akintayo & Our results & Ashok \\
\hline \multicolumn{5}{|l|}{ Physical properties } \\
\hline Specific gravity & 0.902 at $20^{\circ} \mathrm{C}$ & 0.919 at $25^{\circ} \mathrm{C}$ & 0.878 at $20^{\circ} \mathrm{C}$ & 0.879 at $15^{\circ} \mathrm{C}$ \\
\hline Viscosity (Cst) & n. o & 17.1 at $30^{\circ} \mathrm{C}$ & 7.891 at $20^{\circ} \mathrm{C}$ & 4.84 at $40^{\circ} \mathrm{C}$ \\
\hline Density (g/mL) & 0.900494 & n. d & 0.876566 & n. d \\
\hline Refractive index & 1.4710 at $20^{\circ} \mathrm{C}$ & 1.468 at $25^{\circ} \mathrm{C}$ & 1.4570 at $20^{\circ} \mathrm{C}$ & n. d \\
\hline Water content $(\mathrm{Wt} \%)$ & 2.420 & n.d & n.o & $16 \times 10^{-6}(0.16 \mathrm{ppm})$ \\
\hline Ash content $(\mathrm{Wt} \%)$ & 0.168 & n.d & n.d & n.d \\
\hline \multicolumn{5}{|l|}{ Chemical properties } \\
\hline Saponification value & 231.4125 & $198.85 \pm 1.40$ & 312.7575 & n.d \\
\hline Acid value & 2.4123 & $3.5 \pm 0.1$ & 2.5245 & 0.24 \\
\hline
\end{tabular}




\begin{tabular}{|c|c|c|c|c|}
\hline \multirow[t]{2}{*}{ Properties } & \multicolumn{2}{|l|}{ J.curcas oil } & \multicolumn{2}{|l|}{ Biodiesel } \\
\hline & Our results & Akintayo & Our results & Ashok \\
\hline Free fatty acids $(\% \mathrm{~m} / \mathrm{m})$ & $1.092 \leq \mathrm{FFA} \leq 1.221$ & n. $d$ & $1.143 \leq \mathrm{FFA} \leq 1.278$ & n. $d$ \\
\hline Ester value & 229.0 & n. $d$ & 310.233 & n. $d$ \\
\hline Iodine value ( $\mathrm{g}$ of $\mathrm{I} 2 / 100 \mathrm{~g}$ of sample ) & 218.280 & $105.2 \pm 0.7$ & 267.444 & n. $d$ \\
\hline Peroxide value & 1.2 & n. d & 4.4 & n. d \\
\hline Unsaponifiable matters (Wt\%) & 6.0 & $0.8 \pm 0.1$ & 4.0 & n. $d$ \\
\hline \multicolumn{5}{|l|}{ Mineral content } \\
\hline Calcium (ppm) & 302.5 & n. $d$ & n. $d$ & n. $d$ \\
\hline Magnesium (ppm) & 85.0 & n. $d$ & n. $d$ & n. $d$ \\
\hline Phosphorus (ppm) & 79.9 & n. $d$ & n. $d$ & n. $d$ \\
\hline Lead (ppm) & 71.25 & n. $d$ & n. $\mathrm{d}$ & n. $d$ \\
\hline
\end{tabular}

Key to the Table 2: n. o: not obtained; and n. d: not determined

\section{Conclusion}

During the present study a soxhelet extraction has been used for successful extracting Jatropha curcas seeds oil. A yield of $48.8 \%$ was obtained using $n-\mathrm{C}_{6} \mathrm{H}_{14}: \mathrm{CH}_{2} \mathrm{Cl}_{2}$ (9:1) and a duration of 3 hours. Vegetable oils are mainly comprised of esters called triglycerides, which are a combination of saturated and unsaturated fatty acids of different molecular weights with glycerol. When triglycerides react with an alcohol in the presence of an alkaline catalyst, they produce a mixture of methyl esters and glycerol. In order to increase the yield and the quality of produced biodiesel, the experimental results shown that the specific methods of reduction of FFA and water content should be checked. A yield of $85.3 \%$ of biodiesel was obtained within 2 hours of reaction which can be considered as a good result in our condition of work. As the Jatropha curcas crop has very good potential to be grown in Rwanda, it is therefore recommended that the plant should be cultivated on large scale production to produce the oil that can be transmethylated into an acceptable biodiesel. However, Jatropha curcas plants should be cultivated far from the road and not in volcanic soil in order to reduce the nocive metals such as lead. It is well known that biofuels must be held to performance standards that will reduce heat-trapping carbon emissions while protecting the environment. These standards must accurately assess the full global warming impact of transportation fuels, from oil well to wheels for gaso-line and from seeds to wheels for biofuels. Thus, for the improvement of this research work, other chemical studies are recommended using the modern technological methods. Full exploitation of all physico-chemical properties of biodiesel are also needed to be conducted and compared with other results obtained from various soil types.

\section{Acknowledgement}

The Authors thank for facilities availed by the National University of Rwanda (NUR) and the Institute of Scientific and Technological Research (IRST). We also thank Prof. Emmanuel Bajyana (Ex-Dean of the Faculty of Science at NUR) for valuable discussions and suggestions.

\section{References}

[1] Hanny JB, Shizuko H. Biodiesel production from crude Jatropha curcas L. seed oil with a high content of free fatty acids. Bioresource Technology 2008; 99: 1716-1721.

[2] Parawira W. Biodiesel production from Jatropha curcas: A review. Scientific Research and Essays 2010; 5: 1796-1808.

[3] Tint TK, Mya MO. Production of Biodiesel from Jatropha oil (Jatropha curcas) in Pilot Plant. World Academy of Science, Engineering and Technology 2009; 26: 477-483.

[4] Kazi MR, Mohammad M, RoknuzzamanMd, Asadullah AG. Biodiesel from Jatropha Oil as an Alternative Fuel for Diesel Engine. International Journal of Mechanical \& Mechatronics Engineering 2010; 10: 1-6.

[5] Igbokwe JO, Nwaiwu CF. Effect of temperature on methyl ester (Biodiesel) yield from groundnut and Palm Kernel oils. The International Journal of Engineering and Science 2013; 2: 6-8.

[6] Crabbe E, Nolasco-Hipolito CN, Kobayashi G, Sonomoto K, Ishizaki A. Biodiesel production from crude palm oil and evaluation of butanol extraction and fuel properties. Process Biochemistry 2001; 37: 65-71.

[7] Makkar HPS, Becker K, Sporer F, Wink M. Studies on nutritive potential and toxic constituents of different provenances of Jatropha curcas. J. Agric. Food. Chem 1997; 45: 3152-3157.

[8] Emil A, Zahira Y, SitiKartom K, Manal I, Jumat S. Characteristic and Composition of Jatropha curcas Oil Seed from Malaysia and its Potential as Biodiesel Feedstock Feedstock. European Journal of Scientific Research 2009; 29: 396-403.

[9] Inekwe UV, Odey MO, Gauje B, Dakare A, Ugwumma C, Adegbe E. Fatty acid composition and physicochemical properties of Jatropha curcas oils from Edo and Kaduna states of Nigeria and India. Annals of Biological Research 2012; 3: 4860-4864. 
[10] Wilhelm H, Martin M. Detoxification experiments with the seed oil from Jatropha curcas L. Industrial Crops and Products 2000; 12: 111-118.

[11] Ja HL, Sung BK, Hah YY, Young JS, Gyung BK, Woo IJ, et al. Biodiesel production by enzymatic process using Jatropha oil and waste soybean oil. Biotechnol Bioproc E 2013; 18: 703-708.

[12] Gubitz GM, Mittelbach M, Trabi M. Exploitation of the tropical oil seed plant Jatropha curcas L. . Biores.Technol. 1998; 67: 73-82.

[13] Ma F, Hanna MA. Biodiesel production: a review. Bioresource Technology 1999; 70: 1-15.

[14] Gubitz GM, Mittelbach M, Trabi M. Exploitation of tropical oil seed plant Jatropha curcas L. Bioresource Technology 1999; 67: 73-82.

[15] Knothe G, Steidley KR. Kinematic viscosity of biodiesel fuel components and related compounds. Influence of compound structure and comparison to petrodiesel fuel components. Fuel 2005; 84: 1059-1065.

[16] Highina BK, Bugaje IM, Umar B. Biodiesel production from Jatropha caucus oil in a batch reactor using zinc oxide as catalyst. Journal of Petroleum Technology and Alternative Fuels 2011; 2: 146-149.

[17] Antony Raja S, Robinson smart DS, Lindon Robert Lee C. Biodiesel production from Jatropha oil and its characterization. Research Journal of Chemical Sciences 2011; 1: 81-87.
[18] Kosasi S, Van der Sluis WG, Labadie RP. Multifidol and multifidolglucoside from the latex of Jatropha multifida. Photochemistry 1989; 1989: 2439-2441.

[19] Rashid U, Anwar F. Production of biodiesel through optimized alkaline-catalyzed transesterification of rapeseed oil. Fuel 2008; 87: 265-273.

[20] Alamu OJ, Waheed MA, Jekayinfa SO, Akintola TA. Optimal Transeserification Duration for Biodiesel Production from Nigerian Palm Kernel Oil. Agricultural Engineering International: the CIGR Ejournal; Vol.IX; Decemeber, 2007; 4-9.

[21] Chitra P, Venkatachalam P, Sampathrajan A. Optimisation of experimental conditions for biodiesel production from alkali-catalysed transesterification of Jatropha curcas oil. Energy for Sustainable Development 2005; Vol. IX, No. 3: 13-18.

[22] Akintayo ET. Characteristics and composition of Parkiabiglobbossa and Jatropha curcas oils and cakes. Bioresource Technology 2004; 92: 307-310.

[23] Ashok P. Handbook of Plant-Based Biofuels. CRC Press Taylor \& Francis Group, 2008; p297.

[24] Bekir O, Surhid G. Vehicles Air Pollution: Experiences from Seven Latin American Urban Centers. The International Bank for Reconstruction and Development, September 1997; p73. 